\title{
Editorial
}

\section{A Tribute to Nicholas Certo}

I first met Nick Certo in the Fall of 1974 when I began my doctoral program at the University of Wisconsin-Madison. I had been given the opportunity to work with Dr. Lou Brown and his team, and I was pretty intimidated since they were the national leaders in innovative ideas and services for students with severe disabilities. I had just come from working at a state institution in Illinois and had no clue what was going on in this big time-place. Nick took me aside and filled me in on how everything works with Lou and the team and the Madison Public Schools. He was witty, honest, forthright, kind, empathetic, and an incredible advocate for children, as well as loyal to Lou. I will never forget those early months there and the way he reached out.

Over the years we stayed connected professionally, he on the West Coast and me the East Coast, and I never tired of seeing his out of the box thinking, his tenacity, his advocacy and the way he carried on Lou's unwavering determination to change the world and make it a better place for persons with the most severe disabilities.

Probably because of the distance we did not get the face time I think either of us would have liked over the years but it was clear to me that we both knew what each other was doing. I would get these random emails or "reach outs" about this article or that study and I did the same with him with his San Francisco work. He and Rich Luecking (see following tribute) did what I consider to be one the best transition papers (in 2008, Research and Services for Persons with Disabilities) where they introduced, I think for the first time, the term "seamless transition." I have used that term hundreds of times in my own talks as it so adeptly captures what we all shoot for with youth with severe disabilities: easy movement from school to work and adult living.

I last saw Nick at a small research conference about 6 years ago and it was a really great meeting. We shared some old "war stories," talked about progress that had been made in 35 years but also discussed how much further we needed to go. He looked good and we both had a chance to tell each other how much we valued each other's work and contribution and dedication to the field - not something we all get the chance to do enough. Shortly after that I got another reach out, we talked about his health some but as usual he was asking to see if I knew someone in the East Coast where he had a friend whose son might need help and did I know anybody? This was Nick, to the end, trying to help other people.

In the end I can say that Nick Certo left a tremendous legacy for children and youth with severe disabilities, his friends, and providers in the field. He was a leader and a creative thinker who was always looking for solutions. We will all miss him.

Paul Wehman

E-mail:pwehman@vcu.org 